\title{
www.czasopisma.pan.pl \\ The Influence of Mg Additive on the Structure and Electrical Conductivity of Pure Copper Castings
}

\author{
M. Kranc ${ }^{\text {a }}$, G. Sikora ${ }^{\text {b }}$, M. Górny ${ }^{\text {b }}$, A. Garbacz-Klempka ${ }^{\text {b* }}$ \\ ${ }^{a}$ Foundry Research Institute, Zakopiańska 73, 30-418 Kraków, Poland \\ ${ }^{\mathrm{b}}$ AGH University of Science and Technology, Faculty of Foundry Engineering, Reymonta 23, 30-065 Krakow, Poland \\ * Corresponding author. E-mail address: agarbacz@agh.edu.pl
}

Received 28.04.2017; accepted in revised form 18.07.2017

\begin{abstract}
The aim of this paper was to attain defect free, pure copper castings with the highest possible electrical conductivity. In this connection, the effect of magnesium additives on the structure, the degree of undercooling $(\Delta T \alpha=T \alpha-T m i n$, where $T \alpha-$ the equilibrium solidification temperature, Tmin - the minimum temperature at the beginning of solidification), electrical conductivity, and the oxygen concentration of pure copper castings have been studied. The two magnesium doses have been investigated; namely $0.1 \mathrm{wt} . \%$ and $0.2 \mathrm{wt} \%$. A thermal analysis was performed (using a type-S thermocouple) to determine the cooling curves. The degree of undercooling and recalescence were determined from the cooling and solidification curves, whereas the macrostructure characteristics were conducted based on a metallographic examination. It has been shown that the reaction of $\mathrm{Mg}$ causes solidification to transform from exogenous to endogenous. Finally, the results of electrical conductivity have been shown as well as the oxygen concentration for the used $\mathrm{Mg}$ additives.
\end{abstract}

Keywords: Solidification Process, Primary grains, Pure copper, Castings, Mg additive, Electrical conductivity

\section{Introduction}

The use of copper alloy castings is generally reserved for applications that demand the highest electrical and thermal conductivity [1-4]. These pure copper products account for about $70 \%$ of copper use. The remainder is used in the form of copper alloy, mainly brass and bronze [5]. After silver, pure copper has the highest electrical conductivity and is widely used in electronics and electrical engineering as well as in the energy industry [2]. The good thermoelectrical properties of pure copper are of great importance, especially in large electrical connectors, water-coolers, hot blast furnace tuyeres, coils, primary rods, etc $[1,2,5-7]$. There are two possibilities to get the ultimate shape of components made from pure copper. For simple shapes, usually plastic deformation is used, while complex shapes are achieved by the casting of liquid metal into the mold cavity (remelting process).

The manufacturing of pure copper and low-alloyed copperbased castings could be counted as a very difficult technology of melting and pouring. Unalloyed copper presents several casting difficulties, which can lead the metal to obtain a coarse or columnar grain structure [8,9], a rough surface, the tendency for shrinkage, and gas porosity $[1,10]$.

A major problem in the smelting procedure of pure copper is the potential for impurities, which mainly includes oxygen, hydrogen, and phosphorus [10-12]. These are the sources of the occurrence of internal microporosity and macroporosity 
$[5,13]$. The source of these inclusions can be the metal charge, the atmosphere in the furnace and in the foundry, moisture, and even the tools that are used $[1,2,6,7,10]$. The presence of such impurities is highly undesirable because of the lower strength properties due to decreases in the area of the cross section $[14,15]$ as well as reductions in the thermoelectrical and technological properties $[3,16,17]$. Moreover, the presence of inclusions, impurities and porosities in ingots leads to defects in components during plastic deformation of pure copper and has been extensively investigated by many researchers [18-25].

Metallurgical treatments, including the process of deoxygenation, have a significant impact on the microstructure and properties of pure copper castings [10,26-30]. The use of deoxidizing agents (e.g., phosphorous, magnesium) allows us to acquire copper with very low amounts of gases and other impurities.

The literature provides limited data on the relationships among the deoxidizing agent additives, solidification paths, structure, and thermoelectrical properties of pure copper castings. Pure copper castings (for potential use in current transformers and circuit breakers) with different magnesium additives as deoxidizing agents have been produced, and the relationship among the microstructure, macrostructure, thermal analysis, electrical conductivity, and oxygen level results were discussed in order to obtain defect-free components with the highestpossible electrical conductivity.

\section{Experimental}

The melting procedure of copper C11000 (ETP - Electronic tough pitch copper) of high purity was conducted in an induction furnace with a $2.0 \mathrm{dm} 3$ capacity. The melting in the furnace was conducted under a covering of charcoal. The liquid metal was heated to $1200^{\circ} \mathrm{C}$, and then magnesium (of technical purity) in amounts of 0.1 and 0.2 wt.\% was introduced to the melt. The liquid metal was poured into a ceramic shell mold covered with quartz sand at an ambient temperature. The castings were in the form of a cylinder with a diameter of $\phi=40 \mathrm{~mm}$ and a height of $80 \mathrm{~mm}$. The casting melts were conducted under the following conditions: melt I - without the addition of $\mathrm{Mg}$ (base alloy); melt II - the addition of $0.1 \mathrm{wt} . \% \mathrm{Mg}$; and melt III - the addition of 0.2 wt. $\% \mathrm{Mg}$.

A chemical analysis was conducted using the absorption method in a SOLAAR M6 - Thermo spectrometer. In Table 1, the results of chemical analysis are presented.

Table 1

Results of chemical composition for alloys I-III

\begin{tabular}{lll}
\hline \multirow{2}{*}{ Alloy no. } & Element, wt.\% & \\
\cline { 2 - 3 } & $\mathrm{Mg}$ & $\mathrm{Cu}$ \\
\hline I & 0 & Bal. \\
\hline II & 0.07 & Bal. \\
\hline III & 0.16 & Bal. \\
\hline
\end{tabular}

Before pouring, the thermocouples of type S (Pt-PtRh10) were placed in the geometric centers of the mold cavity.
An Agilent 34970A multi-channel electronic module was used to record temperatures, with a time step of $0.05 \mathrm{~s}$.

The samples for metallographic analysis were taken from the geometrical center of the castings, close to the temperature measurement points. Then, a metallographic specimen was prepared. A surface analysis was conducted for the size (dp) and porosities fraction (fp) in the microstructure. Then, the specimens were etched according to the ASTM E407-07 standard (etchant no. 40) for the reveal of the primary grains as well as the estimation of their sizes (dav) and surface densities (NA).

The metallographic examinations were performed using an optical microscope (Leica MEF4M) and stereomicroscope (Leica MZ6) using polarized light. Microanalysis of the chemical composition was performed using a scanning electron microscope (Jeol 5500LV) equipped with an EDS System.

In addition to this, the electrical conductivity (with the use of SIGMATEST 2.069 equipment) and evaluation of the amount of oxygen (with the use of an LECO TCH 600) were determined. Evaluation of the oxygen concentration was conducted by the oxygen extraction in the form of $\mathrm{CO} 2$ particles to a neutral gas (helium) in the process of melting the samples in a graphite crucible placed in the furnace. In the second stage of the measurement, the amount of $\mathrm{CO} 2$ was evaluated by absorption spectroscopy (IR).

\section{Results and discussion}

\subsection{Thermal analysis}

Figure 1 presents the cooling curves of copper in base alloy form and after the addition of 0.1 and $0.2 \mathrm{wt} \% \mathrm{Mg}$, respectively.

The melting procedure of copper C11000 (ETP - Electronic tough pitch copper) of high purity.

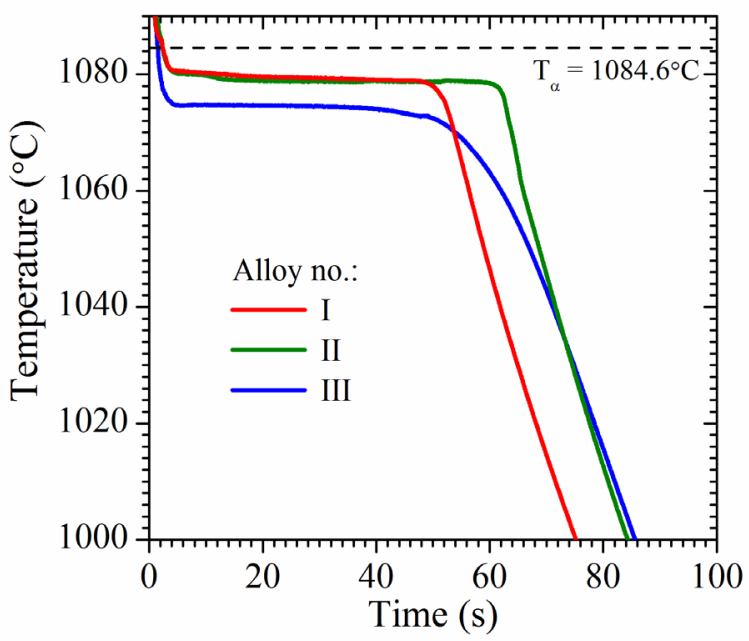

Fig. 1. Cooling curves of copper in base alloy form and after the addition of magnesium 
Results of the thermal analysis show that, in the case of copper in its initial state, the maximum undercooling $(\Delta \mathrm{Tm}=\mathrm{T} \alpha-\mathrm{Tmin}$, where $\mathrm{T} \alpha$ - equilibrium solidification temperature for pure copper and Tmin - minimal temperature at the beginning of solidification) is $3.9{ }^{\circ} \mathrm{C}$. The addition of $0.1 \mathrm{wt} . \% \mathrm{Mg}$ (Alloy II) lowers the temperature of maximum undercooling at the beginning of solidification by $0.5^{\circ} \mathrm{C}$ when compared to its initial state. The highest value of undercooling was achieved with the addition of 0.2 wt. $\% \mathrm{Mg}$ (Alloy III); this amounted to $10{ }^{\circ} \mathrm{C}$. In the case of Alloy II, the cooling curve is very similar to the alloy in its initial state (Alloy I). In Alloy III (0.2 wt.\% Mg), the cooling curve is significantly different (with a recalescence of $\sim 0.2^{\circ} \mathrm{C}$ ) to alloys I and II (with no recalescence). In addition, in alloy III the highest undercooling was achieved (with a value of $6.1{ }^{\circ} \mathrm{C}$ ) compared to the initial state (alloy I). This can be attributed to the influence of $\mathrm{Mg}$ (in the amount of $0.2 \mathrm{wt} . \%$ ) as a liquidus temperature-reducing additive, which results from the $\mathrm{Cu}-\mathrm{Mg}$ phase equilibrium diagram. It is worth nothing that in the $\mathrm{Cu}-\mathrm{Mg}$ phase equilibrium diagram [31], the liquidus slope amounts to $35.3{ }^{\circ} \mathrm{C} / \mathrm{s}$, which means that the addition of $0.2 \% \mathrm{Mg}$ decreases the liquidus temperature by $7.1 \mathrm{oC}$. This temperature value is very close to that real minimal temperature at the beginning of the solidification of alloy II.

\subsection{Structure analysis}

Figure 2 shows the microstructures of investigated alloys.

The measurement of the porosities (surface fraction and average size of gas porosity) are presented in Table 2 .

Table. 2.

The fraction and size of the gas porosities in castings made from Alloys I-III

\begin{tabular}{llll}
\hline Alloy & I & II & III \\
\hline$d_{p}, \mu \mathrm{m}$ & $4.7 \pm 1.3$ & $4.9 \pm 2.0$ & $3.9 \pm 1.0$ \\
\hline$f_{\mathrm{p}}, \%$ & 4.9 & 0.5 & 0.6 \\
\hline
\end{tabular}

where:

$d_{p}$ - average size of the gas porosities,

$f_{\mathrm{p}}$ - area fraction of gas porosity

From metallographic examinations, it follows that the addition of magnesium significantly reduces the occurrence of gas porosities (up than 10x). It needs to be mentioned that the addition of 0.2 wt. $\% \mathrm{Mg}$ does not eliminate gas porosities in the castings, but it even slightly increased it as compared to Alloy II with 0.1 wt. $\% \mathrm{Mg}$.
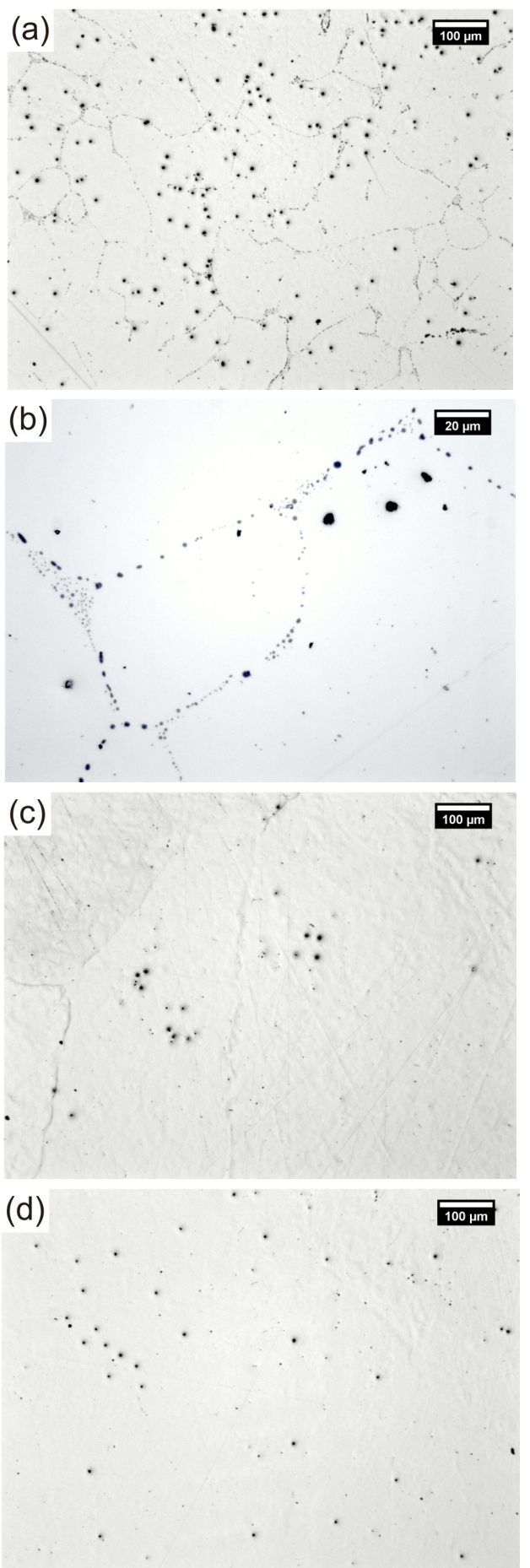

Fig. 2. The microstructures of Alloy I (base alloy) (a) - mag. 100x; (b) - mag. 500x; (c) - Alloy II (addition of 0.1 wt.\% Mg) mag. 100x;(d) - Alloy III (addition of 0.2 wt.\% Mg), mag. 100x, polished samples 
Figure 3 shows the micrograph of SEM microstructure of alloy I. In point 1 (inter-dendritic region) and area 2 (dendrite region) is marked by the colour red colour in the EDS microanalysis.

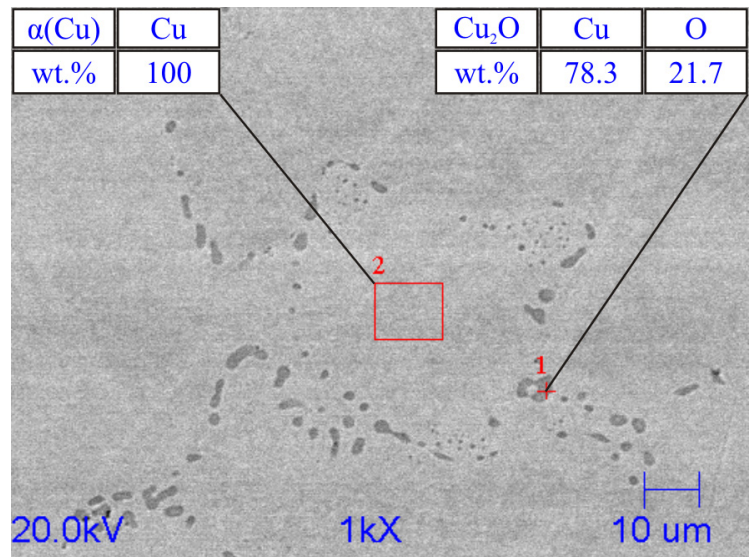

Fig. 3. SEM micrograph of microstructure of an alloy I, together with EDS microanalysis

In the case of Alloy I, one can observe an oxide eutectic $(\mathrm{Cu}+\mathrm{Cu} 2 \mathrm{O})$, which is located at the primary grain boundaries (Fig. 2 a,b and Fig. 3). The presence of oxide eutectic in investigated alloy I indicates, that oxygen content exceeds 80 ppm [31]. The presence of $\mathrm{Cu} 2 \mathrm{O}$ precipitates reduces the final electrical conductivity of cast components.

Within all of the samples, the sizes of the gas porosities are very similar, amounting to $4-5 \mu \mathrm{m}$. They were created in the liquid metal just before solidification. They are mainly distributed inside the dendrites.

Figure 4 shows the macrostructures of the examined castings.

From Figure 4, it follows that the addition of $\mathrm{Mg}$ in the amount of 0.1 wt.\% significantly influences the crystallization of the copper primary dendrites. Additionally, the analysis shows that the addition of $\mathrm{Mg}$ contributes to the transformation from endogenous crystallization (where the primary equiaxed grains are formed) to exogenous crystallization (where columnar grains are formed with a small fraction of equiaxed grains). The increase of $\mathrm{Mg}$ from 0.1 to $0.2 \mathrm{wt} . \%$ causes an enlargement in the primary grains and the almost-complete elimination of equiaxed grains. The average dendrite diameter for the initial state (Alloy I) is dav $=1036 \pm 252 \mu \mathrm{m}$, while the number of dendrite grains per unit area (NA) is $2281 / \mathrm{cm} 2$. In the case of Alloy II, the average dendrite diameter is dav $=2091 \pm 544 \mu \mathrm{m}$, and their number per unit area (NA) is $241 / \mathrm{cm} 2$. The addition of 0.2 wt.\% $\mathrm{Mg}$ (Alloy III) caused an increase in dendrite grain size (width) to $4000-5000 \mu \mathrm{m}$, with columnar lengths of $1000-2000 \mu \mathrm{m}$.
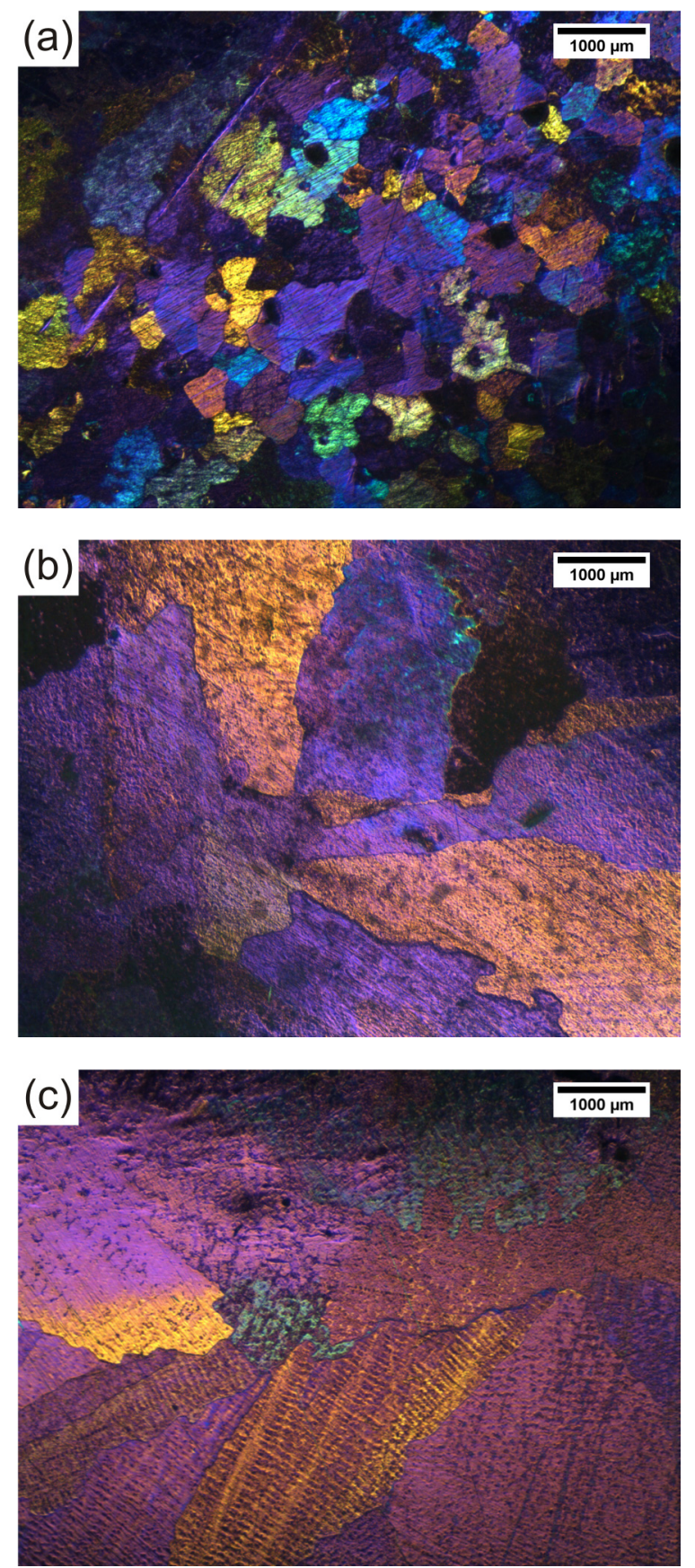

Fig. 4. The macrostructure of copper: (a) Alloy I; (b) Alloy II; and (c) Alloy III, mag. 8x, polarized light 


\subsection{Electrical conductivity and oxygen concentration}

In Table 3, the results of electrical conductivity and oxygen concentration are presented.

Table 3.

The results of electrical conductivity and oxygen concentration in the casting of Alloys I-III

\begin{tabular}{cccc}
\hline Melt & I & II & III \\
\hline $\begin{array}{c}\text { Electrical } \\
\text { conductivity, } \\
\text { \%IACS }\end{array}$ & 86.21 & 89.56 & 82.76 \\
\hline $\begin{array}{c}\text { Oxygen } \\
\text { concentration, } \\
\text { ppm }\end{array}$ & 411 & 56.5 & 76.8 \\
\hline${ }^{1}$ The International Annealed Copper Standard \\
\hline
\end{tabular}

The values of electrical conductivity and oxygen concentration are strictly connected with the casting structure. The highest oxygen concentration is present in the casting from Alloy I, where the oxide eutectic $(\mathrm{Cu}+\mathrm{Cu} 2 \mathrm{O})$ occurs (which is confirmed with a metallographic analysis). The total porosity fraction is estimated at a level of $4.9 \%$ (Table 2). The addition of $\mathrm{Mg}$ resulted in the absence of an oxide eutectic in the casting microstructure. In addition to this, the total porosity (after the Mg treatment) sharply decreases to a level of $0.5 \%$ (which is almost $10 \mathrm{x}$ lower as compared to the initial state; i.e., without $\mathrm{Mg}$ treatment). The lowest oxygen concentration in the castings $(56.5 \mathrm{ppm})$ was attained after the addition of $0.1 \mathrm{wt} . \% \mathrm{Mg}$. The results of oxygen concentration are proportional to the porosity fraction. The changes in the microstructure have an influence on the electric conductivity (Table 3). The highest electrical conductivity (89.56\% IACS) characterizes the castings from Alloy II (with the lowest oxygen content). In the case of Alloy III (with the highest addition of magnesium), electrical conductivity is too low to fullfil the High Conductivity Copper Standard (which is set at 85 $\%$ IACS). In this case, despite the low oxygen content (including area fraction of porosity), lack of copper-oxygen eutectic, and columnar primary structure, the low electrical conductivity can be explained by the impact of adding magnesium, which contributes to the its reduction when dissolved in the metal matrix.

Magnesium is a deoxidation and desulphurizing agent for copper and its alloys. Due to the lower temperatures for $\mathrm{Mg}$ treatment, the reaction is much steadier compared to the traditional spheroidization treatment of ductile iron (spheroidal graphite cast iron) with the use of master alloys containing magnesium. The reaction of $\mathrm{Mg}$ with oxygen has a refining effect that transforms the crystallization mechanism from exogenous to endogenous. This transformation is probably caused by a reduction of the substrates for the nucleation of copper dendrites. Lowering the maximum undercooling (Fig. 1) could be the reason for the lower number of nucleation substrates in the creation of the primary dendritic grains of copper.

\section{Conclusions}

The following conclusions can be drawn from the present investigation:

1. It has been shown that the reaction of $\mathrm{Mg}$ causes a transformation from exogenous to endogenous in the solidification, which is probably the consequence of reducing the substrates for the heterogeneous nucleation of primary dendrites of copper.

2. The conducted research work shows that the addition of $\mathrm{Mg}$ in an amount of 0.1 wt.\% provides the best electricalconductivity conditions, additionally resulting in the lowest amount of oxygen in the casting. This is the reason for the lower occurrence of gas porosity, which does not exceed $0.5 \%$.

3. It has been shown that an excessive addition of $\mathrm{Mg}$ (greater than required) does not increase the quality of casting components, but on the contrary, causes the decrease in electrical-conductivity. This can be attributed to the impact of magnesium as an alloying element, which contributes

to electrical conductivity reduction when dissolved in the metal matrix.

\section{References}

[1] ASM Speciality Handbook, Copper and copper alloys. (2001). ASM International.

[2] Górny, Z. (2011). Copper and copper alloys with high conductivity. Cracow: Instytut Odlewnictwa.

[3] Vincent, C., Silvain, J.F., Heintz, J.M. \& Chandra, N. (2012). Effect of porosity on the thermal conductivity of copper processed by powder metallurgy. J. Phys. Chem. Solids. 73, 499-504.

[4] Chung, W.-H., Hwang, H.-J. \& Kim, H.-S. (2015). Flash light sintered copper precursor/nanoparticle pattern with high electrical conductivity and low porosity for printed electronics. Thin Solid Films. 580, 61-70.

[5] Schlesinger, M.E., King, M.J., Sole, K.C. \& Davenport, W.G. (2011). Chapter 20 - Melting and Casting. In Extr. Metall. Copp. (397-413). 5th ed., Elsevier.

[6] Hsu, Y.T. \& O'Reilly, B. (1977). Impurity effects in highconductivity copper. JOM. 29, 21-24.

[7] Bonderek, Z. \& Rzadkosz, S. (2000). The phenomena of porosity in castings made of aluminium and magnesium alloys. Solidif. Met. Alloy. 2, 51-55.

[8] Lu, L., Shen, Y., Chen, X., Qian, L. \& Lu, K. (2004). Ultrahigh Strength and High Electrical Conductivity in Copper. Science. 304, 422-426.

[9] Habibi, A., Ketabchi, M. \& Eskandarzadeh, M. (2011). Nano-grained pure copper with high-strength and highconductivity produced by equal channel angular rolling process. J. Mater. Process. Technol. 211, 1085-1090.

[10] Romankiewicz, F. (1995). Solidification of Copper and its alloys. Poznań- Zielona Góra: PAN.

[11] Ẑitňanský M. (1995). Refining of the Copper and investment casting. J. Mater. Process. Technol. 53, 499-507. 
[12] Fu, Y., Chen, J., Liu, N., Lu, Y., Li, T. \& Yin, G. (2011). Study of ultrahigh-purity copper billets refined by vacuum melting and directional solidification. Rare Met. 30, 304-309.

[13] Yamamura, S., Shiota, H., Murakami, K. \& Nakajima, H. (2001). Evaluation of porosity in porous copper fabricated by unidirectional solidification under pressurized hydrogen, Mater. Sci. Eng. A. 318, 137-143.

[14] Lun, S., Sin, A. \& Elsayed, C. (2013). Ravindran, Inclusions in magnesium and its alloys: a review, Int. Mater. Rev. 58, 419-436.

[15] Shahzeydi, M.H., Parvanian, A.M. \& Panjepour, M. (2016). The distribution and mechanism of pore formation in copper foams fabricated by Lost Carbonate Sintering method. Mater. Charact. 111, 21-30.

[16] Li, B.Q. \& Lu, X. (2011). The Effect of Pore Structure on the Electrical Conductivity of Ti. Transp. Porous Media. 87, 179-189.

[17] Cuevas, F.G., Montes, J.M., Cintas, J. \& Urban, P. (2009). Electrical conductivity and porosity relationship in metal foams. J. Porous Mater. 16, 675-681.

[18] Gu, C.F., Hoffman, M., Toth, L.S. \& Zhang, Y.D. (2015). Grain size dependent texture evolution in severely rolled pure copper. Mater. Charact. 101, 80-188.

[19] Miyajima, Y., Okubo, S., Abe, H., Okumura, H., Fujii, T., Onaka, S. \& Kato, M. (2015). Dislocation density of pure copper processed by accumulative roll bonding and equalchannel angular pressing. Mater. Charact. 104, 101-106.

[20] Zi, A. (2010). Pure copper processed by extrusion preceded equal channel angular pressing. Mater. Charact. 61, 141144.

[21] Benchabane, G., Boumerzoug, Z., Thibon, I. \& Gloriant T. (2008). Recrystallization of pure copper investigated by calorimetry and microhardness. Mater. Charact. 59, 14251428.
[22] Zhang, Z.H., Wang, F.C., Wang, L., Li, S.K., Shen, M.W. \& Osamu S. (2008). Microstructural characteristics of largescale ultrafine-grained copper. Mater. Charact. 59, 329-333.

[23] Chen, J., Yan, W., Liu, C.X., Ding, R.G. \& Fan, X.H. (2011). Dependence of texture evolution on initial orientation in drawn single crystal copper. Mater. Charact. $62,237-242$.

[24] Han, S.Z., Goto, M., Ahn, J.-H., Lim, S.H., Kim, S. \& Lee, J. (2014). Grain growth in ultrafine grain sized copper during cyclic deformation. J. Alloys Compd. 615, S587-S589.

[25] Han, S.Z., Goto, M., Lim, C., Kim, S.-H. \& Kim, S. (2009). Fatigue damage generation in ECAPed oxygen free copper. J. Alloys Compd. 483, 159-161.

[26] Kuhn, H.-A., Altenberger, I., Käufler, A., Hölzl, H. \& Fünfer, M. (2012). Properties of High Performance Alloys for Electromechanical Connectors, in: Copp. Alloy. - Early Appl. Curr. Perform. - Enhancing Process. InTech, p 51-68.

[27] Konečná, R. \& Fintová, S. (2012). Copper and Copper Alloys: Casting, Classification and Characteristic Microstructures, in: Copp. Alloy. - Early Appl. Curr. Perform. - Enhancing Process., InTech, 3-30

[28] Bydałek, A.W., Bydałek, A. \& Czyż, M. (2000). The rational principle of the copper alloys refining. Solidif. Met. Alloy. 2, 65-71.

[29] Rzadkosz, S., Kozana, J. \& Kranc, M. (2013). Researching the Influence of Chemical Composition and Technological Parameters on the Quality of Copper Alloys. Arch. Foundry Eng. 13, 153-158.

[30] Rzadkosz, S., Kranz, M., Nowicki, P. \& Piękoś, M. (2009). Influence of refining operations on a structure and properties of copper and its selected alloys. Arch. Metall. Mater. 54, 299-304

[31] Baker, H. Ed. (1992). ASM Handbook: Alloy phase diagrams. United States of America: 10th ed., ASM International. 